\title{
O DISCURSO DE SILVA JARDIM NO CONGRESSO DO PARTIDO REPUBLICANO PAULISTA \\ DE 1888.
}

\section{REYNALDO XAVIER CARNEIRO PESSOA \\ Disciplina: História do Brasil.}

\begin{abstract}
"Não desejo para o meu país uma democracia eivada dos mesmos erros da monarquia democrática: não desejo apenas uma substituição de nome; quero uma radical e profunda mudança nas normas de governo".

Dr. Raymundo Sá Valle.

Questão da Chefia do Partido. Manifestos e artigos publicados na Gazeta de Notícias em maiojunho de 1889. Rio de Janeiro, Tip. da Gazeta de Notícias, $1889 . \mathrm{Pg} .21$ ).

(Jardim, Silva - A Situação Republicana.
\end{abstract}

$O$ ano de 1888 desde o seu alvorecer, assistiu uma maior impetuosidade nas contradições que vinham se acentuando no Império a partir de 1850 . O progresso de novas atividades econômicas dando uma nova dinâmica aos centros urbanos mais proeminentes, o crescimento de novas áreas cafeicultoras - oeste paulista -, a entrada de imigrantes em ritmo crescente, a campanha abolicionista sensibilizando vasta camada da população do país, as fugas e revoltas dos escravos ganhando vulto, a substituição da mão-de-obra escrava por iniciativa particular por não ser mais condizente com o momento histórico, alem de outros fatos significativos, demonstram suficientemente a falência do governo monárquico, vivendo já os seus momentos finais, incapaz que era de se ajustar às transformações ocorridas na nação (1) . O cenário apresentava-se propício ao aparecimento e expan-

(1). - Essa posição foi por nós esposada e apresentada de forma mais ampla na tese de doutoramento que defendemos no Departamento de História da Faculdade de Filosofia, Letras e Ciências Humanas da Universidade de Sáo Paulo no dia 4 de janeiro de 1973. Encontra-se este estudo em fase de revisão para uma futura publicação. 
são de idéias que trouxesse consigo mensagens contendo soluções visando a eliminação dos obstáculos oferecidos pela estrutura imperial, escravocrata, conservadora, decadente e desvinculada da realidade.

Nesse quadro assim configurado deu-se a aprovação pela Câmara Municipal de São Borja, a 13 de janeiro de 1888 (2), em redação definitiva, de uma moção sugerindo um plebiscito para que o país se pronunciasse quanto a forma de governo a ser adotada após a morte do imperador Pedro II. Essa proposição obteve uma repercussão que atravessou os limites provinciais do Rio Grande do Sul, alcançando outras regiões brasileiras. O seu texto, embora da autoria do republicano Aparício Mariense, não fazia referência direta à República. Entretanto, o movimento de solidariedade aos edís sul-riograndenses, punidos de imediato pelo Presidente da Província, partiu de maneira mais incisiva dos propagandistas das idéias republicanas.

Um ato público que se efetivou na cidade de Santos a 28 de janeiro do mesmo ano, no Teatro Guaraní (3), marcou o início da adesão dos paulistas aos propósitos dos vereadores do fronteiriço município de São Borja, seguida posteriormente por vários outros centros urbanos, inclusive de outras províncias do Brasil. Teve essa manifestação como personagem central o jovem advogado fluminense Antônio da Silva Jardim que pronunciou uma conferência (4), condenando peremptoriamente a viabilidade de um terceiro reinado, chegando a afirmar ser válida a utilização de todos os meios possíveis para impedir a ascenção ao trono imperial da princesa herdeira e seu esposo.

A partir de então, a propaganda republicana passou a contar com influente participação do causídico de Capivarí. Da praiana cidade santista, Silva Jardim rumou para Campinas onde a 26 de fevereiro se fez presente, igualmente como principal orador, em mais um ato de solidariedade aos vereadores gauchos. Aí manteve ele os argumentos anteriormente defendidos com relação a possibilidade do terceiro reinado (5). Antes, porem, da manifestação da cidade campineira, a

(2). - Ver sobre o assunto: Miranda (Francisco Gonçalves), A Moção Plebiscitária de São Borja contra o terceiro reinado. "Revista do Arquivo Público Municipal". São Paulo, 7 (75): 171-200, abril, 1941; e Pessoa (Reynaldo Carneiro), A Idéia republicana no Brasil, através dos documentos. São Paulo, Editora Alfa-Omega, 1973. Pgs. 92/93.

(3). - Cf. Jardim (Silva), Memórias e Viagens. I-Campanha de um propagandista (1887-1890). Lisboa, Tip. Companhia Nacional, 1891. Pg. 39.

(4). - O texto dessa conferência foi editado sob o título: "A Pátria em Perigo (Braganças e Orleans). São Paulo, Tip. da Província, 1888. 48 p."

(5). - Publicado sob o título: "A Pátria em Perigo (Braganças e Ozleans). Segundo opúsculo (Suplementar). Campinas, Tip. da "Gazeta de Campinas", 1888. 33 p. "Nesta publicação encontra-se tambem, em anexo - 
Câmara de Vereadores da cidade de São Simão, antecipando-se às demais co-irmães paulistas seguiu o exemplo de São Borja, aprovando a 31 de janeiro, da autoria do vereador Manuel Dias Prado, uma indicação que, após as justificativas, estava assim redigida:

"que a Camara Municipal de São Simão, trilhando o caminho constitucional e certa de que interpreta os sentimentos de seus munícipes e de todos os cidadãos que se interessam pelo engrandecimento Brasil, manifeste o desejo de ser consultada a Nação acerca da disposição do artigo $4{ }^{\circ}$ da constituição, que está contido em suas atribuições ex-vi do artigo 58 da sua lei orgânica, a $1^{\circ}$ de outubro de 1828. Sala das Sessões, 31 de janeiro de 1888" (6).

Esta indicação, como disse o Diário Popular (7), demonstrou que o brado sul rio-grandense não estava destinado a morrer sem eco (8).

Logo após ao seu regresso de Campinas à cidade santista, onde residia, Silva Jardim defrontou-se com a notícia do espancamento de um oficial da marinha no Rio de Janeiro. De imediato, aproveitando-se da questão que provocou uma crise militar, promoveu um comício, a 5 de maio, que contou com a presença da oficialidade do cou-

pgs. 25 a 29 -, o discurso pronunciado em Santos a 5 de maio de 1888, no qual conclui com a moção concitando a união do povo com as forças armadas para a luta contra a monarquia, pg. 28. de 1888

(6). - Cf. Diário Popular. Ano IV, n 965. São Paulo, 1 de fevereiro

(7). - Idem,ibidem.

(8). - Fo:am apresentadas indicações, alem de outras, nas seguintes cidades paulistas de São João da Boa Vista, São Vicente, Itú, Itatiba, Casa Branca, Amparo, São Paulo, sendo algumas aprovadas, outras discutidas sem contar com o apôio da maioria. Na Assembléia Provincial, alem da moção condenando a repressão movida pelo Presidente Rodrigues Alves - na época vinculado ao Partido Conservador - contra as Câmaras Municipais, apresentada pelos Republicanos e Liberais, deu-se por parte do deputado republicano Martinho Prado Júnior a apresentação de uma indicação, a apreciação de seus pares, na sessão de 8 de março de 1888 , nos moldes das que haviam sido aprovadas nas mencionadas Câmaras Municipais, não conseguindo aprovação. Ver sobre o assunto: Anais da Assembléia Provincial de São Paulo - Primeiro Ano da 27a Legislatura - Sessão de 1888. São Paulo, Tip. do Correio Paulistano, 1888 (sessões dos dias 21 e 29 de fevereiro, e 3, 5 e 8 de março). Outras manifestações de solidariedade deram-se em outras partes do país e através de outras entidades. Dentre as quais citaremos: Piraí, Rezende, Ouro Fino, Curvelo, Aiuruoca, etc., Clubes Republicanos de Guaratinguetá e São José do Calçado - Espírito Santo e a cobertura de jornais como A Província de São Paulo, Diário Popular - São Paulo, Gazeta Nacional - Rio de Janeiro, $A$ Provincia - Recife (este de orientação liberal), etc. 
raçado Bahia, ancorado no porto de Santos, e usando da palavra, concitou as forças armadas a se unirem ao povo para derrubar a monarquia (9).

Ainda nesse mesmo ano de 1888 , no dia 7 de abril, o tribuno fluminense, a convite do Clube Republicano de São Paulo, proferiu uma palestra alusiva a data (10). Nessa oportunidade ficou evidenciado o aumento do prestígio que o combativo propagandista passava a obter nas hostes republicanas da Província de São Paulo.

Um pouco mais tarde, no mês de maio, quando da realização do Congresso do Partido Republicano Paulista, novamente Silva Jardim veio a capital da Província, desta feita na qualidade de representante do Clube Republicano de Santos, em substituição a Vicente de Carvalho que se encontrava doente. Conquistando o respeito e a admiração dos seus pares, vê-se indicado para figurar ao lado dos velhos baluartes republicanos Rangel Pestana e Américo de Campos na comissão redatora do Manifesto que deveria traçar a linha de ação partidária a ser seguida. Nesse documento, datado de 24 de maio (11), em cuja redação nota-se a nítida influência do representante da cidade litorânea de Santos, foi dado o brado de opção por uma posição mais contundente na propaganda da idéia republicana, sugerindo o emprego de meios que iam alem das recomendações ordeiras e pacíficas do grupo "evolucionista", aceitas até então pela maioria do Partido. Na noite em que foi aprovado o mencionado Manifesto, Silva Jardim usou da palavra e pronunciou um discurso que tornou-se um verdadeiro prefácio à proclamação dos republicanos paulistas. E essa notavel peça oratória que a seguir transcreveremos na íntegra, obedecendo restritamente o seu texto original (12), visando antes de mais nada, uma maior divulgação do documento, hoje raro nos fichários das nossas bibliotecas.

(9). - Foi aprovada o seguinte moção: "O povo de Santos, reunido em "meeting" resolve aderir solenemente à atitude do exército e da armada na questão militar, e convida-os a empenhar o seu valor ao lado dos patriotas populares numa reorganização da nação brasileira." Cf. A Província de São Paulo, $\mathrm{n}^{\circ} 3885$ de 13 de março de 1888 .

(10) . - Publicada em opúsculo sob o título: Salvação da Pátria. Governo Republicano. Santos, Tip. do Diario de Santos, 1888. 48 p.

(11). - O Manifesto do Partido Republicano Paulista de 24 de maio de 1888 encontra-se transcrito na íntegra no livro A Idéia Republicana no Brasil, através dos documentos, obra citada, páginas 94/105.

(12) . - O texto aqui transcrito na íntegra é o do opúsculo Salvação da Pátria (Governo Republicano). Segundo opúsculo suplementar. A Revolução (Discurso pronunciado no Congresso Republicano de São Paulo, em a noite de 24 de maio de 1888). Santos, Tip. do Diário de Santos, 1888. 17 p. 
Silva Jardim

\author{
SALVAÇĀO DA PATRIA \\ (Governo Republicano) \\ Segundo Opusculo (Suplementar)
}

\title{
A REVOLUÇão.
}

Discurso pronunciado no Congresso Republicano de São Paulo, em noite de 24 de Maio de 1888 (12).

Delegado dos republicanos da Cidade de Santos perante o Congresso Republicano, na qualidade de substituto do primeiro representante, então enfermo, proferi naquella reunião, ao discutirse qual a attitude do Partido perante o terceiro reinado, o discurso que hoje sahe á luz da publicidade.

Tendo assumido, desde o começo do anno que corre, uma attitude directamente revolucionaria contra a nova ordem social e politica que se prepara em nosso Paiz, julguei de meu dever expôr francamente aos meus correligionarios minhas opiniōes e meus desejos a respeito; e tive a fo:tuna e a satisfação de vêr que erão os da Assembléa inteira: - pelo discurso que se seguiu, do illustre chefe republicano, dr. F. Rangel Pestana, e pelas resoluções tomadas pelo Congresso, já expostas ao Publico no novo Manifesto do Partido Republicano Paulista.

Possa a publicação d'este trabalho levar os espiritos esclarecidos e os corações patrioticos a meditação que lhes gere esta convicção que todo me possue: - da necessidade, no momento actual, de um pronunciamento enezgico dos Brasileiros para a elimina. ção da Monarquia na America.

Junho de 1888

Silva Jardim

(Sendo-lhe dada a palavra pelo Presidente do Congresso, o sr. dr. Prudente de Moraes, diz o Orador:)

Meus Senhores, eu sustentei há pouco com outros correligionários que esta moção relativa á attitude do Partido Republicano diante do terceiro reinado devia ter preferência na discussão á que se refere á separação da Provincia de S. Paulo do Imperio, porque me parece que todas quantas decisões possamos tomar, dependem da resposta que dermos á pergunta que a moção p:esente envolve. De facto, antes de resolver si nos consentiremos resigna- 
dos a soffrer a monarchia brazileira na nova phase em que ella vai entrar, ou si a combateremos com todas as nossas forças, não poderemos affirmar si nos empenharemos na instituição da Republica Brazileira, ou si na organização da Patria Paulista.

Neste mesmo recinto, em conferencia do Club Republicano, eu já manifestei-me sobre a questão separatista. De accôrdo com a observação historica, que nos ensina o desmembramento, de si irrevogavel, dos estados demasiado vastos, começado no ultimo seculo com a independencia dos Estados Unidos, e continuado com a formação das nações ibero-ame:icanas, não obstante, já no primeiro, já mormente no segundo caso, a identidade da lingoa, do culto e dos costumes, - de accordo com a previsão sociologica, que aconselha esse desmembramento para garantia de ordem e progresso internos e de paz exterior geral, dissipada a possibilidade das invazões, e erguido e amor patriotico, eu sou pola constituição das pequenas nacionalidades, ligadas entre si pela só federação espiritual. E, pois, para o Brazil, cuja extensão é, em verdade, exorbitante, embora eu deseje, primeiro, um conjunto de reformas geraes para toda a communidade, sou pela sua organisação em muitas Patrias; eu quizera, emfim, a unidade da Republica Brazileira, para sua gradual e pacifica desaggregação; nem julgo que possa ser isto irrealisavel e utopico, desde que é o ideal politico scientifico.

Mas, o que acima de tudo sou, é republicano; o que acima de tudo nós somos, é republicanos, é patriotas; o que portanto, acima de tudo nós somos, é adversarios, actualmente inimigos mesmo, da Monarchia em nosso Paiz; o que a todos nos invade é a convição de que ella é hoje um perigo social, um elemento de perturbação e de lucta, pelo seu antagonismo com as aspirações nacionaes, corpo estranho que é no organismo brazileiro; - que nós queremos, portanto, acima de tudo, parece-me, de um modo mais ou menos perfeito, com federação, com unitarismo, ou com separação, é a Republica, é a eliminação da Monarchia, extinção do privilegio de casta, e governo da Opinião. Resta saber, si para instituir o novo regimem politico, queremos combater sem treguas o antigo, na sua nova attitude; si podemos faze-lo; em que terrenos, e com que meios, de sorte a impedir mesmo de instalar se, e muito mais de fixar se, esse terceiro reinado, que tão justamente para nós se affigura triste época em que, ao lado da desordem administrativa, da orgia financeira e da politica corruptora, caracteristicos do governo do Imperador moribundo, teremos a oppressão material do militarismo e do argentarismo, personificados no Principe Esposo, e a oppressão moral do bea- 
terio papista, encarnado na futura Imperatriz: - tyrannia á fortuna, tyrannia ao trabalho, e tyrannia ao pensamento: imposto exorbitante, recrutamento forçado, e perseguição ás convicções.

Tenho confiança, Senhores, que o Partido Republicano não quererá outra cousa, si não oppôr-se completamente a essa situação. Não creio mesmo que as palavras do nosso illustre correligionário que declara a moção mera these rhetorica, e que parece duvidar tenhamos forças para assumir uma attitude de inteira hospitalidade perante 0 terceiro reinado, sejam outra cousa sinão o estratagema do chefe experiente, que na vespera da batalha sonda os animos, que estuda o terreno, que incita á lucta os soldados, fingindo menospreso pelo seu valor para melhor atear nelles a aspiração do combate com a victoria. Não me parece que o partido republicano paulista tenha sido um partido de "parola", como é claro que não tem sido um partido de revolução: julgo sim ter-se elle constituido um agremiamento de propaganda pacifica contra as instituições monarchicas, usando por armas a conviç̧ão esclarecida, o auxilio calmo e constante á marcha da evolução brazileira e humana, que certamente nos leva ao governo republicano; seria grande injustiça apoda-lo de paroleiro, seria desconhecer sua influencia sobre a mentalidade paulista, e mesmo patria. Penso, porém, ser tempo em que esse partido, sem sahir radicalmente de seu programa evolutivo, se prepare para a acção, pela comprehensão bem exacta do que se deva entender pressa evolução.

De facto, Senhores, a evolução das sociedades humanas, não é o que espiritos sem patriotismo, ou pouco intelligentes e pouco profundos, inspirados por um egoismo commodo, falsamente em nome da sciencia social, tem querido fazer comprehender á massa dos cidadãos que abraça a doutrina republicana, de fé, de desejo de regeneração; não é uma fatalidade independente em absoluto da acção do homem, como por exemplo aquelia pela qual um corpo lançado no espaço irrevogavelmente cahe para a terra. E certo que tudo está sujeito a leis, e que, objecto da evolução humana, somos a elles sujeitos, do mesmo modo que a Humanidade; é certo que o homem se agita e essa grande existencia o gua; - mas não é menos certo que para completar as leis são necessarias vontades; de sorte que - homem é tambem um agente da evolução social, o qual pode por sua acção acelerar-lhe ou retardar-lhe a marcha, e cujo concurso directo, é, pois, necessario para toda a transforma- 
ção, mormente para a transformação politica, pratica, das instituições, e dos actos.

Nem mesmo, a evolução humana no seu apogêo de aperfeiçoamento pođerá excluir a Revolução. De um modo geral, depois da descoberta das leis sociologicas que demonstraram ter chegado a sociedade ao terceiro estadio de sua intelligencia, a demonstração, de sua actividade, a paz, e de seus sentimentos, a fraternidade, e que ensinaram ser a politica uma sciencia, e se governarem os paizes, não pelo dedo de Deus ou pela vontade unica das multidões, e sim pelas leis sociaes, completas por vontades competentes, pode-se affirmar que está fechada a era das revoluções systhematicas; mas concluir d'ahi que a Sociedade d'ora avante fará sua ascenção para a perfectibilidade com a magestosa serenidade da rotação de um astro, sem abalos nem convulsões, é desconhecer a natureza dos seus elementos, os homens, sêres perfectiveis, mas por isso mesmo mudaveis, sujeitos á tormenta das paixões, em favor do mal, ou em favor do bem. Da mesma arte que é utopico querer banir do organismo phisico a molestia, assim é impossivel banir do o:ganismo social a revolução. Ella consistirá mesmo, eternamente, o supremo recurso da massa popular, do proletariado, fraco pela riqueza, mas poderoso pelo numero, contra as imposições do poder politico tyrannico, ou do poder moral sem mo.alidade. Os mesmos pontifices catholicos reconheceram, na sua admiravel perscrutação da natureza humana, a necessidade de systhematizar a insurreição, já que viam impossivel eliminar do coração do homem essa garantia de liberdade e esse dever excepcional.

Quão felizes seriamos nós, si na Patria B:azileira não nos tivesse obrigado o patriotismo a lançar mão d'esse recurso extremo! Quão felizes si a actual situação do Paiz não nos coagisse ainda a emprega-lo para a instituição do Governo Republicano! O Fundador da Sociologia, Augusto Comte, meditava para seu Paiz applicação de politica mais scientifica, mais ordeira, e pois, mais aconselhavel: a transformação da Monarchia em Republica, pelo p:oprio Imperador, então Napoleão III, urgido, na hypothese, pela opinião publica, em que a Philosophia do Reformador teria feito escola, sob sua grande acção e propaganda. No Brazil, da mesma sorte, por uma applicação da theoria fundamental, o Monarcha, ao impulso da opinião, abdicando do privilegio hereditario de casta, e operando igual transformação, indicaria á Nação um Successor, que ella, de um ou de outro modo, confirmaria. Mas a opinião republicana positivista não se formou de modo a pezar sobre os governos, pela fatalidade da morte do 
Reformador: de sorte que só pelo desgraçado abalo de 1870 voltou sua Patria ao governo republicano; e entre nós, pela tardia e difficil divulgação de sua doutrina, não temos feita essa opinião, quando, entretanto, o actual Imperador está á morte, e pretendem subir os degráos do throno um Principe ex-patriado e guerreiro: - pertubador; e uma Princeza fraca e beata: - incapaz; ambos ameaça aos destinos da Patria, que, sem exagero, pode ser dita em verdadeiro perigo. Pois si seria ingenuidade imbecil ou criminosa má fé affirmar a capacidade de Gastão de Orléans e de Izabel para tamanha previdencia politica, e tão alta missão social, pois si a revolução não se pode fazer pelo alto, pois si a massa da Nação por si e por seus orgãos competentes pede altamente reformas, e reformas, que absolutamente não podem ser adiadas sob pena de anarchia profunda, e si o poder é incapaz de realiza-las, porque todas levariam á eliminação da propria monarchia, - só nos resta o segundo meio de reformar, de baixo para o alto, a reforma pela Revolução, pela intimacão popular. Si a Revolução Franceza, des que não foi realizado o plano de Turgot, que a faria do governo, foi justificada, porque não o seria a $\mathrm{Re}$ volução Brazileira, produzida por um povo em circumstancias si não identicas pela mizeria e oppressão soffridas, similhantes comtudo pelo desejo de progresso e de bem estar impedido sempre, e para o qual é tão claramente destinado pela natureza que o cerca, pela raça que o produziu, e pelo organismo phisico e moral que élhe riqueza, amor e gloria?

Acima de tudo, Senhores, está o amor á Patria. O principio da fraternidade, que manda a Paz, é feito para facilitar a expansão d'esse amor, não para empece-lo. Acima de tudo está o dever de servir a essa Patria: a politica scientifica, que manda a Ordem, é feita para melhor realização d'esse serviço, não para obsta-lo. A politica scientifica não póde mesmo excluir em absoluto a violencia. Como a indignação e a revolta, a violencia nem sempre é condemnavel: paz não quer dizer apathia, sciencia não quer dizer indifferença, fraternidade não quer dizer impudor perante as affrontas. Até os santos se indignaram; até os sabios se revoltaram por vezes. Augusto Comte foi o fundador da Sociologia, foi o revelador da politica scientifica, mas, quando Napoleão III planejou sua transformação de chefe de Republica em Imperador, elle levantou-se de modo tão energico contra o restabelecimento do Imperio, que articulou, nesse momento mesmo, e diante de testemunhas, os motivos sociaes e politicos que "condemnavam a Napoleão III, e podiam fazer-lhe caber a sorte de Carlos I de Inglaterra", isto é, a execução: e com o Senador francez Vieil- 
lard, seu consectario, teve larga e solemne conferencia em que aconselhou-o, quando se propuzesse o restabelecimento da monarchia em favor dos Bonapartes, pedisse a prisão do principe indigno e a sua conducção a Vincennes para ahi ser julgado; Vieillard não teve a energia inteira para um tamanho dever, mas uma voz, uma só, votou no Senado contra a restauração imperial: - essa voz foi a sua: - e acontecia isto em 1852; e a sceincia social estava fundada, e o tempo das revoluções parecia acabado. Triste sciencia seria essa, Senhores, a que nos isolasse nos gabinetes, deixando nossa Patria entregue aos botes dos ambiciosos vulgares que fazem do poder um instrumento de prazer, e um meio de renda escandaloso!

O ultimo termo d'uma evolução é mesmo, Senhores, um acto revolucionario. Evolução implica progresso. É ce:to que o progresso não é uma modificabilidade infinita, como o pensam alguns, o que alteraria a ordem fundamental, e sim uma modificação no que existe, resultante da propria natureza das cousas, e sujeita a uma certa lei: o progresso é o desenvolvimento da ordem. Mas nas epocas anormaes, como aquella que atravessa o Occidente inteiro, em que ha do antigo regimem muito a pôr abaixo, todo o progresso, toda a reforma, implica um acto de energica destruição, um acto revolucionario, condição da substituição consequente. $O$ que nós temos sempre visto, já em nossa Patria, já nas outras, é que, quer a reforma parta espontaneidade dos governos, quer parta da exigencia da opinião pública, é sempre feita "ex-abrupto", de modo a alarmar os espiritos conservadores da Sociedade. No nosso paiz mesmo o que foram sinão actos revolucionarios, embora abençoados por todos os brazileiros, a lei de 28 de Setembro de 1871, que libertou o ventre da mulher escrava, iniciativa do poder, e a lei de 13 de maio de 1888 , que aboliu a escravidão, exigencia popular? 0 estadista unico que planejara preparar-lhes a marcha natural, José Bonifacio, o velho, viu seu admiravel projecto cahir em esquecimento. O puro empirismo dá lugar a estas revoluções fataes. Os directores politicos se succedem no poder sem a menor continuidade nos serviços publicos: o imperante é, ou uma vontade perturbadora e egoista, ou que simula retrahir se, á espreita do pensamento nacional; mas um plano de governo não acompanha a sua intervenção; - de modo que um bello dia a necessidade de instituiçōes liberaes inspira ao primeiro ministro adventicio, accorde com a vontade real, uma medida de progresso: é imposta de sorpreza quasi á massa nacional que a não aguarda: - acto revolucionario. Ou então a opinião publica faz-se pelos seus orgãos cabeça da sociedade: con- 
versa, discute, escreve, ora, reclama, exige, grita, impõe: o governo atterrorisado, medroso da anarchia, do aniquilamento das instituições, ou cede, ou cahe, realisando-se sempre 0 ideal desejado: - acto revolucionario. E o que nós vemos em nosso paiz: é o que a imprevidencia de microscopicos homens de Estado nos tem sempre preparado. Foi o que se deu na questão servil: é o que se dará na questão de forma de governo.

Porque, é ou não certo que a Monarchia é um factor isolado na sociedade brazileira? Tem ella o apoio theologico, clerical? Não tem. Tem o apoio methaphisico, academico? Não tem. Tem o apoio dos homens de sciencia? Não tem. Tem o apoio dos partidos? Não tem. Tem o dos sentimentos do Paiz? Não. O dos seus costumes? Não. O da força publica? Duvidoso. Mas é ou não certo que, na sua applicação, a Monarchia nos tem sido um governo resistente ao progresso? Não tivemos até há pouco a escravidão do homem? Não temos a igreja mantida pelo estado? Não temos um pessimo ensino superior? Não temos uma geral ignorancia da instrucção primaria? Não temos as provincias pessimamente divididas? pessimamente administradas? pessimamente representadas? um parlamentarismo vão? as finanças desorganizadas? o territorio desconhecido? o littoral desapproveitado? As industrias sem impulso? a lavoura inculta? o comercio abalado? os limites indecisos? o proletariado desprotegido? Mas é ou não certo que a Monarchia mostra-se incapaz de garantir a ordem? Que as provincias tendem á desaggregação, á sublevação? Que a autoridade é desrespeitada? Que a propriedade é sophismada? Que as povoações são victimas de desordens? Que não são policiadas? Que as forças estão indisciplinadas? A magistratura sem segurança? Que as guerras serão possiveis, quasi certas? Que o desamor pelo throno levará ao desamor pela Patria e que a Patria será talvez fracamente defendida? Que as instituições fundamentaes da sociedade correm perigo, pois que a instituição monarchica, que não é fundamental, leva tudo á corrupção, á apathia, á decomposição, ou á revolta? Mas é ou não certo que os nossos governadores aggravaram ainda mais a nihilidade das instituiçōes? Que Pedro I inclinou se para o maior despotismo? Que Pedro II durante meio seculo de reinado tendeu para a maior inercia? Que é incompetente Izabel I para governar?... E ou não o sr. Conde d'Eu um espirito bellicoso, dominador e retrogado? Será ou não elle o nosso Imperador? $E$ ou não exacto que a casa de Bragança não nos apresenta homem a substitui lo? E ou não exacto que não possuimos outra dynastia no Paiz? Que seria o maio: dos absurdos inventar uma, ou importa-la do estrangeiro? Mas será ou não exacto que 
o sr. Conde d'Eu não é capaz de nos dar um governo livre, pacifico, progressista, mas sim de empenhar a nação no argentarismo, no militarismo e no clericalismo? E ou não um uzurario esse Pricipe? um guerreiro? um devoto? Será apto á transformação da dictadura monarchica em republicana? Da abdicação do privilegio de casta? - Mas, afinal, pode o Brazil dispensar essa transformação de monarchia em Republica? Não póde. E si a não pode dispensar, poderá faze-la pelo Governo? Não poderá. Como ha de faze la então? - pelo Povo: pela Revolução.

Falais em Ordem, dir-me-ão, e appellais para a Revolução. Que os tranquillos, isto é, os indifferentes, não se assustem, e que os logicos, isto é, os sophistas, não se irritem. Haverá nesse susto e nessa irritação medo da palavra, e falsa comprehensão da palavra. Revolução é a desordem geral numa sociedade, quando a falta de unidade nos actos, e nas idéas, é uma resultante da falta de generosidade dos sentimentos, pela auzencia de uma doutrina altruistica commum: - é o nosso estado, como o de todo o Occidente, estado fatal que os republicanos soffremos, sem o ter exclusivamente creado; estado que continuará no nosso paiz, qualquer que seja sua forma de governo, Monarchia ou Republica, até que uma crença scientifica commum dirija todos os espiritos. Revolução é, politicamente falando, o levantamento em massa de um paiz ou de parte de um paiz afim de derribar a instituição politica, com ou sem apoio da nação inteira, por meio das armas no campo da batalha, ou por meio dos pronunciamentos nos parlamentos, na praça publica, nas reuniōes, na imprensa, na tribuna, pelos artigos, pelos pamphletos, pelos livros, pelos discursos, pelas prelecções, pelas interpellações representativas, pela intimação ultima e positiva ao chefe do Estado para a obtenção de um certo fim: - temos na nossa historia exemplos da revolução armada em 1817, em 1824, em 1842 e em 1848; temos um exemplo d'esta revolução menos violenta, mas não menos efficaz e energica, sustentavel comtudo, em caso de necessidade, pela força armada: - 07 de Abril. A Revolução armada suppõe uma guerra civil, suppõe hostilidade tambem armada de parte da nação; si bem que eu a admire em bellas passagens de nossa historia e da historia da Humanidade, comtudo o meu espirito republicano, fraternal, só extremamente urgido aceitaria e aconselharia esse morticinio, embora de indignos compatriotas. Mas o segundo aspecto da revolução, com o apoio tacito ou expresso do paiz inteiro, apoio que se manifesta pela sua imprensa, pela sua tribuna, pelo seu voto contrario ao elemento monarchio, revolução de que temos exemplo proveitoso no nosso 7 de Abril, revo- 
lução em que pequenas escaramuças e motins inevitaveis não tiram - caracter geral de paz ao movimento, revolução que muna-se mesmo da milicia necessaria para sustentar-se, e que, no caso de opposição, não trepide diante da violencia para com os mais retrogrados elementos da nossa sociedade, essa eu não trepido em aconselha-la, convicto de que o Paiz é republicano, de que as forças republicanas não devem medir-se apenas pelas do partido correspondente, convicto de que a Republica é idéa, sciente ou inscientemente, pouco importa, assás alastrada no vasto espirito anonymo nacional. Essa revolução eu não hesitaria em auxilia-la com as minhas poucas forças, convicto de que seria geral, como o indicam diversos movimentos passados, em pontos os mais diversos do paiz, convicto de que a Monarchia não tem por defensores, e defensores sem fé na propria causa, sinão os membros da Familia Imperial. Os bons Cidadãos, meus Senhores, ou viriam trazer o seu concurso á obra a cuja vanguarda nos collocassemos nós, ou nos olhariam com prudente, mas sympathica e adhesiva espera; - os máos, os roedores humanos, que em todos os tempos solapam suadamente o thesouro material, intellectual e moral da Patria, a raça dos aduladores, essa alimentaria a esperança do goso e da delapidação na nova ordem política: - ergueriam acclamações aos que chegassem ao tôpo da montanha... Para ser completamente claro, direi que aconselho um movimento de opinião, uma agitação de propaganda, que, reagindo sobre o elemento central do paiz, possa impor, numa marcha a $\mathbf{S}$. Christovam, á Senhora Princeza Regente - a abdicação ou a deposição, e ao Principe Esposo, o exilio, ou, no caso de resistencia, a execução. A execução: porque é perdição o sentimentalismo em politica: a pena de morte deve existir para este caso extremo: o do "mais sujo dos crimes" : - a traição á Patria. Mas eu tenho convicção de que a Senhora Princeza abdicaria, e de que o Principe se exilaria; de que a Nação não se veria a braços com uma guerra civil; de que, ensinados pelo exemplo das dissenções que impossibilitaram as Regencias, e que nos fizeram cahir no $2^{\circ}$ Imperio, mais educados hoje, seriamos mais unidos e patiotas, de modo a possuir a Republica.

E erro suppor que esse periodo, embora de difficuldades e de provas, trouxesse a desordem. As nações são como os individuos: a molestia accidental não exclue a vitalidade longa e nativa. Maior abalo que a instituição da Republica, que afinal, reduz se, como destruição, a apear do poder uma familia sem apoio da nação, está causando a abolição da escravidão, medida necessaria sem duvida, mas em nada economicamente preparada, e 
que deu a prova do como o governo guarda a fidelidade á sua palavra. Porque o certo é que a monarchia praticou um bem: mas trahiu a lavoura. Neste caso foram muitos os individuos feridos em seus interesses; no da substituição da forma de governo serão todos inte:essados favoravelmente, e só um grupo perderá em seus lucros inconfessaveis de privilegio e de renda hereditarios. Comtudo, Senhores, outro erro dos falsos evolucionistas, é suppor que a mudança politica se fará sem ataque á instituição fundamental, ou ás pessoas imperiaes, como si fez a abolição da escravidão. Aqui tratava-se de uma reforma social, em que o throno, embora em perigo, poderia sobrenadar acima dos destroços da instituição maldita; agora não, é de uma reforma politica propriamente que nos occupamos, em que $o$ atacado é o proprio throno, que deve afundar no nada desse te-rivel desprezo dos tempos. Si a revolução abolicionista fez se nos quilombos e nas fazendas, a revo'ução politica preciza ser feita nas ruas, e em torno dos palacios do Imperante e de seus ministros... Nada póde dispensar, portanto, um movimento francamente revolucionario. Que resista o governo á nossa acção theorica para que se opere a nossa revolta pratica, ou que, num dado momento, entremos per nós no terreno dessa revolta pratica: - sempre um movimento revolucionario

Para isso, nossa primeiza necessidade é uma imprensa que fale linguagem clara, comprehensivel, terminante, franca, decidida ao combate; será o appello ao povo, a formação decisiva da opinião republicana. Nossa necessidade é a aggremiação de todas as forças do partido republicano, já quanto aos elementos materiais pecuniarios, já quanto á sua disciplinação. Nossa necessidade é a reaç̧ão da nossa propaganda sobre o conjunto da Cidade do Rio de Janei:o, é a arregimentação do espirito republicano naquella Cidade; pois, si, sem desconsideração para com os nossos correligionarios fluminenses, podemos dizer que si a Independencia partiu de São Paulo, a Republica tambem de São Paulo partirá, comtudo é certo que, alem do apoio das forças abertamente irmãs, muito careceremos do apoio do elemento popular fluminense, que secretamente comnosco sympathisa; e a Historia nos mostra que de todos os nossos movimentos politicos o que pela sua sede, teve mais prompto e mais seguro exito, foi o de 7 de abril: demais, parece de bôa regra militar atacar-se o inimigo onde elle se acha; cerca-lo no seu reducto, impondo-se-lhe a capitulação. Nossa necessidade, afinal, quer para a destruição, quer para a organisação immediatamente poste:ior, é a comunicação continua e constante com os nossos correligionarios de outras provincias, 
e em particular com os nossos valentes irmãos rio grandenses, com os nossos tradicionaes irmãos mineiros, com os nossos esperançosos irmãos fluminenses... Assim, fico em que o triumpho será certo. O momento e o mais opportuno para a instituição da Republica no Brazil, é o mais adequado para a sua instituição sem grande abalo social; a nação inteira está mesmo á espera de um novo estado de couzas, sente se nas vesperas de uma reorganisação. O partido dito conservador invade o terreno das reformas liberaes, o partido libe:al arvora a bandeira da federação, que bandeira arvoraremos nós? Certo que ça da Republica immediata, e pois a da Revolução. Estejamos, Senhores, á altura do momento historico, sejamos politicos habeis, façamos a Revolução para fazer a Republica, para fazer a Ordem e o Progresso da Patria. O perigo em que ella se acha de perder o regimem de Liberdade e de Trabalho, pela oppressão clerical e pela guerra, deve eliminar nosso patriotismo para a lucta victoriosa, ou para o martyrio!

Quanto a mim, Senhores, para juntar á palavra á resolução, vos direi que estou ao vosso dispor, quer para morrer no combate, balbuciando as esperanças de futuro, quer para no dia do triumpho entoar as acclamações da victoria; - irei á Cidade em que resido, despedir-me-ei da esposa e dos filhos, e virei collocar-me ao lado dos companheiros

(O Orador é muito applaudido e cumprimentado).

REYNALDO XAVIER CARNEIRO PESSOA. - Nasceu no Engenho Macacheira, na Ilha de Itamaracá, Estado de Pernambuco, em 1929. Bacharel e Licenciado em Geografia e História (1954) e Ciências Sociais (1962) pela Faculdade de Filosofia de Pernambuco da Universidade do Recife (atual Universidade Federal de Pernambuco); Pós-Graduado (1967) e Doutor - Tese: $O$ Ideal republicano e seu papel histórico no segundo reinado (Periodo 1870-1889) (1972), em História, pela Faculdade de Filosofia, Letras e Ciências Humanas da Universidade de São Paulo.

Publicou, entre outros trabalhos:

A Idéia republicana no Brasil através dos documentos (Textos para seminários). São Paulo, Alfa Omega, 1973.

Diálogo entre um Corcunda, um Constitucional e um Federativo do Equador: um raro e curioso documento. São Paulo, s. e., 1975 (Coleção Revista de História - Textos e Documentos n 1). 